QL

557

S53S3 ENT. 


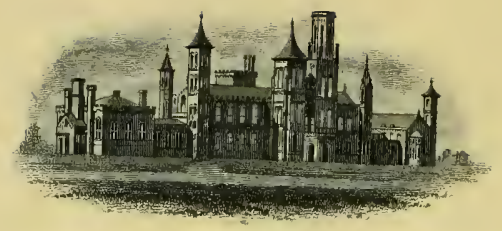

COLLECTION OF WILLIAM SCHAUS

\author{
() \\ PRESENTED \\ TO THE \\ NATIONAL MUSEUM \\ MCMV
}




$$
\text { is lenes }
$$



50353

Ent.

\section{ON A COLLECTION}

OF

\section{SIERRA LEONE LEPIDOPTERA.}

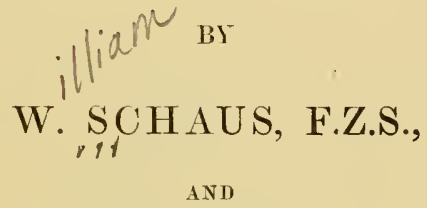

W. G. Clemen'ts, Surgen-Captain A.M.S.

I.ONDON:

R. H. PORTER, 18 PRINCES STREET, CAVENDISH SQUARE, W. 1893. 


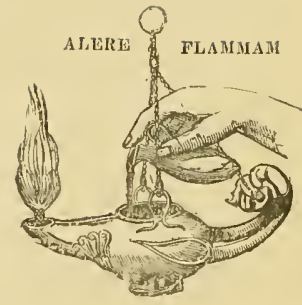

PRINTED BY TAYLOR AND FRANCIS, RED LION COURT, FLEET STREET. 


\section{N T R O D U C T I O N.}

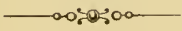

The Lepidoptera whieh are eatalogued and described in the following pages were eolleeted by me during a tour of service of thirteen months' duration at Sierra Leone, West Afriea, in the year's 1891-9?.

With few exeeptions their habitat was the rocky peninsula of Sierra Leone, whieh has an area of some twenty square miles. It is very hilly, some of the hills rising to a height of from 3000 to 4000 feet. The immediately surrounding country is flat and swampy, and, so far as I had an opportunity of judying, is poor in Lepidoptera. Owing probably to its elevation, Sierra Leone is very rich in representatives of the genus Charaxes. In the limited time at my disposal I obtained eighteen speeies-nineteen, ineluding Palla (Charaxes) varanes-with both sexes in fifteen of these.

In eonsequence of my having lost the notes I made at the time on the natural habits of the insects eolleeted, the observations whieh I am enabled to make must neeessarily be brief, fragmentary, and quoted from memory. They may be divided roughly into two elasses: the first eomprising those which have remained in aristoeratie solitude, and are essentially sylvan in their habits; the seeond elass, those which seem to prefer the vieinity of man and his habitations. Of this latter the more noticeable are the Zygrenidæe amongst 
the Heterocera, and D. chrysippus, various species of Mycalesis and Precis, H. daclalus, H. misippus (female comparatively rare), Terias sp., and $P$. demoleus, menestheus, phorcas, leonidas, and pylades. The more distinctly WestAfrican genera (Pseudacraa, Euryphene, Euphadra, Aterica, Cymothö, Epitola) and the Ethiopian ones (Lachnoptera, Salamis, Euxanthe, and Charaxes) confine themselves to the woods and forests.

The butterflies of the genus Aterica fly sedatcly along shaded paths and among the trees, keeping near to the ground and frequently settling. They are gregarious insects, and three or four are fond of resting together, when, but for the presence of the female opis, which is conspicuously banded with yellow, they would be difficult to distinguish.

The Euphedre fly swiftly through the lower branches of the trces. A glcam of sunlight piercing the foliage lights them up for an instant and then they disappear, having scttled either on the upper surface of a leaf or on the leaves covering the ground.

The members of the genus Euryphene have similar habits to those of Aterica, but their flight is stronger. A variety of the female, which is larger and has the upper surface of its hind wings of a golden-green colour, has the figures "1881" vcry distinctly marked in black on the superior surface of the secondaries, " 18 " being in one and " 81 " in the other discoidal cell.

The mamner of flight of the genus Epitola is similar to that of Iolaus. They kecp flying round in small but gradually widcning circles in open patches in forcsts, keeping some thirty or morc feet from the ground; they select the most sunlit side of a tree, on the leaves of which they frequently rest and bask in the sun.

A female of Papilio antimachus was brought to me in December 1891. It had been eaught by hand, by a child, in a garden of a village a few miles from Freetown whilst 
settling on a flower. It was in perfect condition, but, to $\mathrm{my}$ surprise, was smaller than the male. A short deseription of a female antimachus from the Gaboon River appears in the 'Entomologieal Monthly Magazine' for June 1892, p. 162. A very fine male was eanght in June of that year by Lieut. Sterens, of the WVest India Regiment, in front of the Military Sanitarium, on Kortright Hill, whieh is about a thousand feet above sea-level. It had settled on a stone, and flew away on being approached; euriously enough it returned to the same spot on the following day and was then eaptured. This inseet is of rare oeeurrenee at Sierra Leone. The females of many of the butterflies are either rare, or, what is more probable, keep themselves in retirement. The male of $P$. phorcas abounded everywhere, but I only obtained two speeimens of the female, and these eame from the forests elothing the less frequented hills.

The year is divided into two well-marked seasons at Sierra Leone, the wet and the dry. During the former from 170 inehes to over 200 inehes of rain may fall, and but few Lepidoptera are met with on the wing. At its conelusion, in November, species new to one who has only resided there during the preeeding six or seven months make their appearanee; even during the dry season, Norember to May, butterflies do not seem to oeeur in any great profusion. The Pierinæ are but sparsely represented, and there are none of those migratory flights of butterflies whieh are noted as oecurring in Ceylon and the West Indies. The most striking of this family to the eye is Tachyris chloris; it is gregarious, often seleets the vieinity of running water, over whieh it eireles in a wavy, graeeful flight; its eolours of white, orange, and sooty black forming a notableeontrast to the dark green foliage and sparkling water. Another butterfly whieh is very pleasing to wateh is the long-tailed Hypolycana lebona as it flies with an easy deliberation through the elosest thickets. 
Of the females of $P$. merope I obtained but one variety. This is indistinguishable on the wing from Amauris niavius; the malc keeps within the shady parts of the forest and has a bold, lofty, and sailing flight. Selecting an open glade it will fly rapidly up and down for a space of some 300 yards, coming fearlessly near to one's net, which it generally manages to evade by a quick double, and finally, approaching a tuft of grass or the projecting branch of a bush, disappears. It almost invariably selects a broad-bladed grass, striped with brown and yellow, and, hanging pendent from its extremity with the wings folded, the upper ones being eovered over and conccaled by the lower, it cannot be seen until it is again startled into flight. Another butterfly, in this case the female, which scleets a resting-plaec whieh effeetually conceals it, is Catopsilia florella; this yellow insect has small round silvery spots, surrounded by a narrow brown margin on its wings. When near a mango-tree, of which some few of the leaves are of a bright ycllow colour, dotted with spots identical in colour, shape, and disposition with those above described, it invariably selects these leaves for settling oll, and is then very difficult to deteet.

In bringing these few notes to a conclusion I would wish to express my great indebtedness to Mr. William Schaus, F.Z.S., for his very kind help and assistance in "working up" the Lepidoptcra which I brought back from Sierra Lcone. The descriptions of new specics are from his pen. Mr. H. H. Druce was also so kind as to look over and name some of the Lycænidæ. Other new species, including a few Rhopalocera, will, we hope, be deseribed shortly.

W. G. CLEMENTS, SURgeon-Captatn A.M.S.

February 1893. 


\section{ON A COLLECTION}

\section{OF \\ SIERRA LEONE LEPIDOPTERA.}

Fam. N Y M P H A L I D E.

Subfam. DANAIN无.

Danais chrysippus.

Papilio chrysippus, Linn. Mus. Ulr. p. 263.

Amauris damocles.

Papilio damocles, Beauv. Ins. Afr. Am. p. 239, t. 6. f. $3 a, b$.

Amauris hecate.

Danais hecate, Butl. Proc. Zool. Soc. Lond. 1866, p. 44. Amauris niavius.

Papilio niavius, Linn. Mus. Ulr. p. 253.

Subfam. SATYRINE⿸.

Gnophodes parmeno.

Gnophodes parmeno, Doubl. \& Hew. Gen. D. L. p. 363, t. 61 . f. 2.

Gnophodes morpena.

Gnophodes morpena, Butl. Cat. Sat. B. M. p. 7, n. 2. 
Melanitis leda.

Papilio leda, Linn. Syst. Nat. i. 2. p. 773.

Mycalesis saga.

Mycalesis saga, Butl. Cat. Sat. B. M. p. 130, t. 3. f. 1.

Mycalesis vulgaris.

Mycalesis vulgaris, Butl. Cat. Sat.'B. M. p. 130, t. 3. f. 2.

Mycalesis tænias.

Mycalesis tanias, Hew. Ex. Butt. v. Myc. \& Idiom. f. 66.

Xpthima itonia.

Ypthima itonia, Hew. Trans. Ent. Soc. ser. iii. vol. ii. p. 287, t. 18 . f. 13.

Xpthima dolecta.

Ypthima dolecta, Kirby, Proc. Roy. Dubl. Soc. (2) ii. p. 336 .

Subfam. ELYMNIINE.

Elymnias bammakoo.

Elymnias bammakoo, Westw. Gen. D. L. p. 405, n. 12, note.

Subfam. ACR EIINE.

Telchinia eponina.

Papilio eponina, Cram. Pap. Ex. iii. t. 268, A, B.

Telchinia bonasia.

Papilio bonasia, Fabr. Syst. Ent. p. 464.

Acræa quirina.

Papilio quirina, Fabr. Spec. Ins. ii. p. 36.

Acræa lycia.

Papilio lycia, Fabr. Syst. Ent. p. 464.

Acræa camœna.

Acraa camœna, Dru. Ill. Ex. Ert. ii. t. 7. f. 2. 
Acræa egina.

Papilio egina, Cram. Pap. Ex. i. t. 39, F, G.

Acræa pseudegina.

Acrea pseudegina, Westw. Gen. D. L. p. 531.

Acræa orina.

Acrea orina, Hew. Ex. Butt. v. Acr. t. 7. ff. 4:3, 48.

Acræa peneleos.

Acrea peneleos, Ward, Ent. Mo. Mag. viii. p. 60.

Acræa pentapolis.

Acrea pentapolis, Ward, Ent. Mo. Mag. viii. p. 60.

Acræa circeis.

Papilio circeis, Dru. Ill. Ex. Ent. iii. t. 18. ff. 5, 6.

Acræa zetes.

Papilio zetes, Linn. Syst. Nat. i. 2. p. 766.

Acræa salambo.

Acrea salambo, Smith, Ann. Nat. Hist. (5) xix. p. 62.

Planema lycoa.

Acrea lycoc, Godt. Ene. Méth. ix. p. 239.

Planema euryta.

Papilio euryta, Linn. Mus. Ulr. p. 221.

Planema umbra.

Papilio umbra, Dru. Ill. Ex. Ent. iii. t. 18. ff. 1, 2.

Planema gea.

Papilio gea, Fabr. Spec. Ins. ii. p. 32.

Subfam. NYMPHALIN E.

Atella columbina.

Papilio columbina, Cram. Pap. Wx. iii. t. 238, A, B.

Lachnoptera iole.

Papitio iole, Fabr. Spec. Ins. ii. p. 78. 
Hypanartia delius.

Papilio delius, Dru. Ill. Ex. Ent. iii. t. 14. ff. 5, 6.

Pyrameis cardui.

Papilio cardui, Linn. Faun. Suec. p. 276.

Junonia clelia.

Papilio clelia, Cram. Pap. Ex. i. t. 21, E, F.

Junonia cebrene.

Junonia cebrene, Trim. Trans. Ent. Soe. 1870, p. 353.

Precis sinuata.

Precis sinuata, Plötz, Stett. ent. Zeit. xli. p. 477.

Precis octavia.

Papilio octavia, Cram. Pap. Ex. ii. t. 135, B, C.

Precis amestris.

Papilio amestris, Dru. Ill. Ex. Ent. iii. t. 20. ff. 3, 4.

Precis terea.

Papilio terea, Dru. Ill. Ex. Ent. ii. t. 18. ff. 3, 4.

Precis sophia.

Papilio sophia, Fabr. Ent. Syst. iii. 1. p. 248.

Precis orthosia.

Precis orthosia, Klug, Symb. Phys. t. 48. ff. 8, 9.

Precis cloantha.

Papilio cloantha, Cram. Pap. Ex. iv. t. 338, A, B.

Salamis cytora.

Salamis cytora, Doubl. \& Hew. Gen. D. L. t. 25. f. 5.

Salamis anacardii.

Papilio anacardii, Linn. Mus. Ulr. p. 236.

Eurytela dryope.

Papilio dryope, Cram. Pap. Ex. i. t. 78, E, F. 
Eurytela ethosea.

Papilio ethosea, Dru. Ill. Ex. Ent. iii. t. 37. ff. 3, 4.

Hypanis ilithyia.

Papilio ilithyia, Dru. Ill. Ex. Ent. ii. t. 17. ff. 1, 2.

Cyrestis camillus.

Papilio camillus, Fabr. Spec. Ins. ii. p. 11.

Hypolimnas misippus.

Papilio misippus, Linn. Mus. Ulr. p. 264.

Hypolimnas salmacis.

Papilio salmacis, Dru. Ill. Ex. Ent. ii. t. 8. ff. 1, 2.

Hypolimnas dubius.

Papilio dubius, Beauv. Ins. Afr. Amér. p. 238, t. 6 . f. $2 a, b$.

Hypolimnas anthedon.

Diadema anthedon, Doubl. Ann. Nat. Hist. xvi. p. 181 (1845).

Godartia eurinome.

Papilio eurinome, Cram. Pap. Ex. i. t. 70, A.

Pseudacræa semire.

Papilio semire, Cram. Pap. Ex. iii. t. 194, B, C.

Pseudacræa lucretia.

Papilio lucretia, Cram. Pap. Ex. i. t. 45, C, D.

Pseudacræa dolomena.

Diadema dolomena, Hew. Ex. Butt. iii. Diad. t. 2. f. 4.

Pseudacræa boisduvalii.

Diadema boisduvalii, Doubl. Ann. Nat. Hist. xvi. p. 180 (1845).

Pseudacræa epigea.

Pseudacrea epigea, Butl. Cist. Ent. i. p. 214.

Catuna crithea.

Papilio crithea, Dru. Ill. Ex. Ent. ii. t. 16. ff. 5, 6. 
Catuna cœnobita.

Hesperia cœnobita, Fabr. Ent. Syst. iii. 1. p. 247.

Neptis melicerta.

Papilio melicerta, Dru. Ill. Ex. Ent. ii. t. 19. ff. 3, 4.

Neptis agatha.

Papilio agatha, Cram. Pap. Ex. iv. t. 327, A, B.

Neptis nemetes.

Neptis nemetes, Hew. Ex. Butt. iv. Nept. t. 1. ff. 1, 2.

Euryphene sophus.

Papilio sophus, Fabr. Ent. Syst. iii. 1. p. 46.

Euryphene plautilla.

Euryphene plautilla, Hew. Ex. Butt. iii. Eur. t. 3. ff. 14, 15.

Euryphene phantasia.

Euryphene phantasia, Hew. Ex. Butt. iii. Eur. t. 2. ff. 9-11.

Euryphene sœmis.

Euryphene sœmis, Hew. Ex. Butt. iii. Eur. t. 1. ff. 1, 2.

Euryphene tentyris.

Euryphene tentyris, Hew. Ex. Butt. iii. Eur. t. 5. ff. 2 I, 22.

Euryphene gambiæ.

Euryphene gambic, Feisth. Ann. Soc. Ent. Fr. 1850, p. 251, t. 9. f. 2 .

Euryphene brunhilda.

Euryphene brunhilda, Kirby, Ann. Nat. Hist. (6) iii. p. 247.

Euphædra perseis.

Papilio perseis, Dru. Ill. Ex. Ent. ii. t. 21. ff. 3, 4.

Euphædra zampa.

Romaleosoma zampa, Westw. Gen. D. L. p. 281.

Euphædra ceres.

Papilio ceres, Fabr. Syst. Ent. p. 504. 
Euphædra janassa.

Papitio janassa, Lim. Mus. Ulr. p. 294.

Euphædra francina.

Nymphatis fiancina, Godt. Enc. Méth. ix. p. 390, n. 141.

Euphædra harpalyce.

Papilio harpalyce, Cram. Pap. Ex. ii. t. 145, D, E.

Euphædra xypete.

Romaleosoma xypete, Hew. Ex. Butt. iii. Rom. t. 2. ff. 8-10.

Euphædra inanum.

Romaleosoma inanum, Butì. Cist. Ent. i. p. 158.

Euphædra arcadius.

Papilio arcadius, Fabr. Ent. Syst. iii. 1. p. 151.

Euphædra agnes.

Romaleosuma agnes, Butl. Proc. Zool. Soc. Lond. 1865, p. 672.

Hamanumida dædalus.

Papilio darlalus, Fabr. Syst. Ent. p. 482.

Aterica ampedusa.

Aterica ampedusa, Hew. Ex. Butt. iii. At. \& Euryphene, t. 5. ff. 3-5.

Aterica veronica.

Paptlio veronica, Cram. Pap. Ex. iv. t. 325, C, D.

Aterica cupavia.

Papilio cupavia, Cram. Pap. Ex. iii. t. 193, E, F.

Aterica opis.

Papitio opis, Dru. Ill. Ex. Enit. ii. t. 18. ff. 5, 6.

Cymothoë cænis.

Papilio cenis, Dru. Ill. Ex. Ent. ii. t. 19. ff. 1, 2. Cymothoë sangaris.

Nymphalis sangaris, Godt. Enc. Méth. ix. p. 384. 
Cymothoë egesta.

Papilio egesta, Cram. Pap. Ex. i. t. 46, B, C.

Cymothoë usilda.

Harma usilda, Hew. Ex. Butt. iv. Har. t. 4. ff. 13, 14.

Charaxes epijasius.

Charaxes epijasius, Reiche, Ferr. Gal. Voy. Abyss., Ent. p. 469, t. 32 . ff. 1,2 .

Charaxes pollux.

Papilio pollux, Cram. Pap. Ex. i. t. 37, E, F.

Charaxes castor.

Papilio castor, Cram. Pap. Ex. i. t. 37, C, D.

Charaxes brutus.

Papilio brutus, Cram. Pap. Ex. iii. t. 241, E, l.

Charaxes lucretius.

Papilio lucretius, Cram. Fap. Ex. i. t. 82, E, F.

Charaxes protoclea.

Charaxes protoclea, Fcisth. Amn. Soc. Ent. Fr. 1850, p. 260.

Charaxes anticlea.

Papilio anticlea, Dru. Ill. Ex. Ent. iii. t. 27. ff. 5, 6.

Charaxes candiope.

Nymphalis candiope, Godt. Enc. Méth. ix. p. 353, n. 10.

Charaxes etesipe.

Nymphalis etesipe, Godt. Enc. Méth. ix. p. 355, 11. 19.

Charaxes tiridates.

Papilio tividates, Cram. Pap. Ex. ii. t. 161, A, B.

Charaxes numenes.

Charaxes numenes, Hew. Ex. Butt. ii. Nymph. t. 2. ff. 9-11. 
Charaxes ameliæ.

Charaxes amelia, Doum. Rev. Zool. 1861, p. 171, t. ว. f. 1 .

Charaxes mycerina.

Charaxes mycerina, Godt. Enc. Méth. ix. p. 369, n. 65.

Charaxes smaragdalis.

Charaxes smaragdalis, Butl. Proc. Zool. Soc. Lond. 1865, p. 630 , t. 36 . f. 5 .

Charaxes imperialis.

Charaxes imperialis, Murr. Trans. Ent. Soc. 1874, p. 531.

Charaxes alladinis.

Charaxes alladinis, Butl. Cist. Ent. i. p. 5.

Charaxes eupale.

Papilio eupale, Dru. Ill. Ex. Ent. iii. t. 6. f. 3.

Charaxes zingha.

Papilio zingha, Cram. Pap. Ex. iii. t. 315, B, C (178:).

Palla ussheri.

Palla ussheri, Butl. Trans. Ent. Soc. 1870, p. 124.

Palla (Charaxes) varanes.

Papilio varanes, Cram. Pap. Ex. ii, t. 160, D, E.

Palla lichas.

Palla lichas, Doubl. \& Hew. Gen. D. L. t. 49. f. 3.

\section{Subfam. LIBYTH}

Libythea labdaca.

Libythea labdaca, Westw. Gen. D. L. p. 413, t. 68. f. 6. 
Fam. L Y C $Æ$ N I D $A$.

Epitola urania.

Epitola urania, Kirby, Ann. \& Mag. Nat. Hist. (5) xix. p. 4.4.

Epitola teresa.

Epitola teresa, Hew. Ent. Mo. Mag. vi. p. 86.

Epitola dewitzi.

Epitola dewitzi, Kirby, Aun. Nat. Hist. (5) xix. p. 442.

Epitola badura.

Epitola badura, Kirby, Ann. Nat. Hist. (6) iv. p. 271.

Epitola versicolor.

Epitola versicolor, Kirby, Ann. Nat. Hist. (5) xix. p. 444.

Epitola, sp.?

Epitola, sp.?, near Pinodes, H. H. Druce.

Argiolaus ælianus.

Argiolaus elianus, Stg. Iris, iv. p. 148.

Argiolaus belli.

Argiolans belli, Hew. Ann. Nat. Hist. (4) xiii. p. 382.

Argiolaus laon.

Argiolans laon, Hew. Ill. Diurn. Lep., Supp. p. 28, pl. iv. fi. $46, .7 \%$.

Castalius isis.

Papilio isis, Dı'u. Ill. Ex. Ent. ii. t. 3. ff. 4, 5.

Lycænesthes larydas.

Papilio larydas, Cram. Pap. Ex. iii. t. 28:, H.

Lycænesthes lysicles.

Lycenesthes lysicles, Hew. Trans. Ent. Soc. 1874, p. 348.

Lycænesthes moncus.

Papilio moncus, Fabr. Spec. Ins. ii. p. 113. 
Lycænesthes amarah.

Polyommatus amarah, Guér. Laf. Voy. Abyss. vi. p. 38 t, t. 11. ff. 5, 6 .

Lycænesthes sichela.

Lycena sichela, Wallengr. Lep. Rhop. Caffr. p. 37.

Lycæna cissus.

Polyommatus cissus, Godt. Enc. Méth. ix. p. 683.

Lycæna juba.

Papilio juba, Fabr. Mant. Ins. p. 82.

Lycæna lingeus.

Papilio lingeus, Cram. Pap. Ex. iv. t. 379, F, G (J 782).

Lyycæna parsimon.

Papilio parsimon, Fabr. Syst. Ent. p. 526.

Lycæna telicanus.

Papilio telicanus, Hübn. Eur. Schmett. i. ff́. 371, 372, 553,554 .

Lyæna lysimon.

Lyccena lysimon, Hübn. Eur. Schmett. i. ff. 534, 535.

Lycæna knysna.

Lycana knysna, Trimen, Trans. Ent. Soc. ser. iii. vol. i. p. 282.

Lycæna cyclopteris.

Lamprospilus cyclopteris, Butl. Ann. Nat. Hist. (4.) xviii. p. 483.

Lycæna docilis.

Lycana docilis, Butl. Proc. Zool. Soc. Lond. 188\%, p. $5 \tau 1$.

Cyaniris micylus.

Papilio micylus, Cram. Pap. Ex. iii. t. 282, F, G.

Epamera iaspis.

Epamera iaspis, H. H. Druce, Ann. Mag. Nat. Hist. (6) vol. v. p. 50. 
Plebeius gussfeldtii.

Plebeius gussfeldtii, Dewitz, Nova Acta, B. xli. p. 11, no. 2 , p. 206, t. xxvii. f. 12.

Larinopoda muhata.

Larinopoda muhata, Smith \& Kirby, Rhop. Ex. Lyc. pl. ii. ff. 1-4.

Tingra preussi.

Tingra preussi, Staud. Ex. Schmett. p. 267.

Axiocerces perion.

Papilio perion, Cram. Pap. Ex. iv. t. 379, B, C.

Zeritis fallax.

Zeritis fullax, Sharpe, Ann. Mag. Nat. Hist., July 1890, p. 104.

Zeritis latifimbriata.

Zeritis latifimbriata, Sharpe, Ann. Mag. Nat. Hist., July 1890, p. 105.

Zeritis bicolor.

Zeritis bicolor, Sharpe, Ann. Mag. Nat. Hist., Sept. 1891, p. 241 .

Myrina silenus.

Papilio silenus, Fabr. Syst. Ent. p. 531, n. 378.

Myrina genuba.

Myrina genuba, Hew. Ent. Mo. Mag. xii. p. 106.

Myrina nomion.

Myrina nomion, Stg. Iris, iv. p. 156, pl. j. f. 11.

Spindasis clymenus.

Spindasis clymenus, H. H. Druce, Ent. Mo. Mag. xvii. p. 259.

Aphnæus orcas.

Papilio orcas, Dru. Ill. Ex. Ent. iii. t. 34. ff. 2, 3. 
Aphnæus natalensis.

Aphnceus natalensis, Doubl. \& Hew. Gen. D. I. t. 75. f. 4.

Pseudaletis trifasciata.

Pseudaletis trifasciata, Sharpe, Ann. Nat. Hist., July 1890, p. 103 ; Trans. Ent. Soc. p. 556, pl. xviii. f. 8.

Deudorix galathea.

Thecla galathea, Swains. Zool. Ill. ii. t. 69.

Deudorix deritas.

Deudorix deritas, Hew. Trans. Ent. Soc. 1874, p. 352.

Deudorix anta.

Lycena arta, Trim. Trans. Ent. Soc. ser. iii. vol. i. p. 402.

Iolaus eurisus.

Iolaus eurisus, Cram. Pap. Ex. iii. t. 221, D, E.

Iolaus iasis.

Iolaus iasis, Hew. Ill. D. L. p. 42, t. 19. ff. 11, 12.

Iolaus iulus.

Iolaus iulus, Hew. Ill. D. I. Suppl. p. 9, t. 4. ff. 4l-43.

Iolaus calisto.

Anthene calisto, Doubl. \& Hew. Gen. D. L. t. 75. f. 6.

Iolaus timon.

Papilio timon, Fabr. Mant. Ins. ii. p. 65.

Hypolycæna philippus.

Hesperia philippus, Fabr. Ent. Syst. iii. 1. p. 283.

Hypolycæna lebona.

Hypolycana lebona, Hew. Ill. D. L. p. 51, n. 9, t. 23. ff. $28,29$.

Hypolycæna antifaunus.

Iolaus antifaunus, Doubl. \& Hew. Gen. D. Is. t. 75 . f. 1. в 2 
Hypolycæna hatita.

Hypolycena hatita, Hew. Ill. D. L. p. 51, t. 23. ff. 21-24. Hypolycæna eleala.

Hypolycæna eleala, Hew. Ill. D. L. p. 52, t. 23. ff. 25-27.

Hypolycæna hymen.

Papilio hymen, Fabr. Syst. Ent. p. 519.

Hypolycæna mera.

Hypolycœna mera, Hew. Ent. Mo. Mag. x. p. 124.

Hypolycæna naara.

Hypolyccena naara, Hew. Ent. Mo. Mag. x. p. 124.

Hypolycæna gracilis.

Hypolycana gracilis, Stg. Iris, iv. p. 152, pl. i. f. 9.

Hypolycæna zela.

Hypolycana zela, Hew. Ill. D. L. Suppl. p. 14, n. 22, t. 5. ff. 41-43.

Pseudodipsas dewitzii.

Pseudodipsas dewitzii, Stg. Iris, iv. p. 155, pl. i. f. 10.

Fam. P A P I L I O N I D A.

Subfam. PIERINא,

Nychitona alcesta.

Papilio alcesta, Cram. Pap. Ex. iv. t. 379, A.

Terias zoe.

Terias zoe, Hopff. Ber. Verh. Ak. Berl. 1855, p. 640, n. 5 .

Terias senegalensis.

Terias senegalensis, Boisd. Sp. Gén. i. p. 672.

Pieris calypso.

Papilio calypso, Dru. Ill. Ex. Ent. ii. t. 17. ff. 3, 4.

Pieris hedyle.

Papilio hedyle, Cram. Pap. Ex, ii. t. 186, C, D. 
Tachyris chloris.

Papilio chloris, Fabr. Syst. Ent. p. 473, n. 129.

Tachyris rhodope.

Papilin rhodope, Fabr. Syst. Ent. p. 473, n. 130.

Tachyris sylvia.

Papilio sylvia, Fabr. Syst. Ent. p. 470, 1. 115.

Eronea poppea.

Papilio poppea, Don. Nat. Rep. ii. t. 54. f. 2.

Eronia pharis.

Pieris pharis, Boisd. Sp. Gén. i. p. 443.

Eronia argia.

Papilio argia, Fabr. Syst. Ent. p. 470.

Catopsilia florella.

Papilio florella, Fabr. Syst. Ent. p. 479.

Teracolus arethusa.

Papilio arethusa, Dru. Ill. Ex. Ent. ii. t. 19. If. 5, 6.

\section{Subfam. PAPILIONINAE.}

Papilio antimachus.

Papilio antimachus, Dru. Ill. Ex. Ent. iii. t. 1.

A female in perfect condition.

Papilio leonidas.

Papilio leonidas, Fabr. Syst. Ent. iii. 1. p. 35.

Papilio tynderæus.

Papilio tynderceus, Fabr. Syst. Ent. iii. 1. p. 35.

Papilio latreillanus.

Papilio latreillanus, Godt. Enc. Méth. ix. p. 44.

Papilio menestheus.

Papilio menestheus, Dru. Ill. Ex. Ent. ii. t. 9. ff. 1, 2. 
Papilio demoleus.

Papilio demoleus, Limn. Mas. Ulr. p. 214.

Papilio antheus.

Papilio antheus, Cram. Pap. Ex. iii. t. 234, B, C.

Papilio pylades.

Papilio pylades, Fabr. Syst. Ent. iii. 1. p. 34.

Papilio bromius.

Papilio bromius, Doubl. Ann. Nat. Hist. xvi. p. 176 (1845).

Papilio nireus.

Papilio nireus, Linn. Mus. Ulr. p. 217.

Papilio phorcas.

Papilio phorcas, Cram. Pap. Ex. j. t. 2, B, C.

Papilio merope.

Papilio merope, Cram. Pap. Ex. ii. t. 151, A, B.

Papilio cynorta.

Papilio cynortes, Fabr. Syst. Ent. iii. 1. p. 37.

Papilio zenobia.

Papilio zenobia, Fabr. Syst. Nnt. p. 503. n. 255.

Papilio cypræafila.

Papilio cypreafila, But!. Ent. Mo. Mag. v. p. 60.

Fam. II E S P E R I D

Ismene forestan.

Papilio forestan, Cram. Pap. Ex. iv. t. 391, E, F.

Ismene pisistratus.

Hesperia pisistratus, Fabr. Syst. Ent. iii. 1. p. 345.

Ismene iphis.

Papilio iphis, Dru. Ill. Ex. Ent. ii. t. 15. ff. 3,4 . 
Ismene bixæ.

Papilio bixa, Linn. Mus. Ulr. p. 335 .

Pamphila philander.

Carystus philander, Hopff. Ber. Verh. Ak. Berl. 185̃, p. 643.

Proteides helops.

Papilio helops, Dru. Ill. Ex. Ent. iii. t. 33. ff. 2, 3.

Pamphila borbonica.

Hesperia borbonica, Boisd. Faun. Mad. p. 65, n. 3, t. 9. ff. 5,6 .

Pamphila ignita.

Pamphila ignita, Mab. Bull. Soc. Ent. Fr. (5) vii. pl. xl.

Ceratrichia phocion.

Papilio phocion, Fabr. Spec. Ins. ii. p. 138.

Pardaleodes edipus.

Papilio edipus, Cram. Pap. Ex. iv. t. 366, E, F.

Pardaleodes laronia.

Hesperia laronia, Hew. Desc. Hesp. p. 35.

Fam. S P H I N G I D A.

Subfam. MACROGLOSSINAS.

Cephonodes hylas.

Sphinx hylas, Linn. Mant. Plant. p. 539.

Macroglossa trochiloides.

Macroglossa trochiloides, Butl. Proc. Zool. Soc. Lond. 1875 , p. 5.

Macroglossa falkensteinii.

Macroglossa falkensteinii, Dewitz, Mitth. Münch. Ent. Ver. iii. p. 23 , t. 1. f. 1 . 
Lophura pylas.

Sphinx pylas, Cram. Pap. Exot. iii. t. 206, A.

Diodosida iapygoides.

Ocyton iapygoides, Holl. Trans. Amer. Ent. Soc. xvi. p. 60, t. 2. f. 5 .

Antinephele anomala.

Nephele anomala, Butl. Ann. Nat. Hist. (5) x. p. 434.

\section{Subfam. CHEROCAMPINE.}

Basiothia medea.

Sphinx medea, Fabr. Spec. Ins. ii. p. 143, n. 19.

Chœrocampa eson.

Sphinx eson, Cram. Pap. Exot. iii. t. 226, C.

Charocampa gracilis.

Chœrocampa gracilis, Butl. Proc. Zool. Soc. Lond. 1875, p. 8, t. 2. f. 2 .

Chørocampa charis.

Chœrocampa charis, Walk. Cat. Lep. Het. B. M. viii. p. 136, n. 15.

Chœrocampa osiris.

Sphinx osiris, Dalm. Anal. Ent. p. 48, n. 21.

Chørocampa balsaminæ.

Chœrocampa balsamina, Walk. Cat. Lep. Hct. B. M. viii. p. 138, n. 18.

Chœrocampa clotho.

Sphinx clotho, Dru. Ill. Ex. Ent. ii. t. 28. f. 1.

Daphnis nerii.

Sphinx nerii, Limn. Syst. Nat. i. p. 490, n. 5. 


\section{Subfam. AMBULICINEE.}

Nephele æquivalens.

Pachylia equivalens, Walk. Cat. Lep. Het. B. M. viii. p. 191, n. 5 .

Nephele bipartita.

Nephele bipartita, Butl. Ann. Nat. Hist. (5) ii. p. 455.

Nephele œnopion.

Orneus cenopion, Hübn. Samml. Ex. Schmett. ii.

Nephele variegata.

Nephele variegata, Butl. Proc. Zool. Soc. Lond. 1875, p. 15.

Nephele funebris.

Sphinx funebris, Fabr. Ent. Syst. iii. 1. p. 371, n. 47.

\section{Subfam. SPHINGINE.}

Protoparce solani.

Sphinx solani, Boisd. Faune Madag. p. 76, t. 11. f. 2.

Protoparce convolvuli.

Sphinx convolvuli, Linn. Syst. Nat. i. p. 490, n. 6.

\section{Subfam. MANDUCIN E.}

Manduca atropos.

Sphinx atropos, Linn. Syst. Nat. i. p. 490, n. 8.

\section{Subfam. SMERINTHIN 压.}

Basiana postica.

Basiana postica, Walk. Cat. Lep. IIet. B. M. viii. p. 237, n. 3.

Basiana stigmatica.

Basiana stigmatica, Mab. Buull. Soc. Zool. France, ii. 1. 491. 
Fam. A G A R I S T I D E.

Anaphela terminatis.

Eusemia terminatis, Walk. Cat. Lep. Het. B. M. vii. p. 1587.

Xanthospilopteryx euphemia.

Noctua euphemia, Stoll, Pap. Ex. iv. t. 345, A.

Massaga maritona.

Massaga maritona, Butl. Proc. Zool. Soc. Lond. 1868, p. 224, t. $17 . \mathrm{f} .1$.

Massaga delicia.

Massaga delicia, Butl. Proc. Zool. Soc. Lond. 1868, p. 224, t. 17. f. 2.

Egocera boisduvalii.

Agocera boisduvalii, Latr., Cuvier, Règne Anim. (ed. 11) iii. t. 20. f. 3.

EEgocera leucomelas.

Phcegorista leucomelas, Herr.-Schäff. Aussereur. Schmett. i. ff. $22,23$.

EEgocera leona, sp. nov. (Plate I. fig. 1.)

Primaries above brown; at the base a large white spot starting from the costal margin and extending to the middle of the wing above the submedian vein; just beyond the cell a small white transverse spot not reaching the costa; between these spots some transverse velvety brown shades, and a submarginal, very angular, velvety brown line: underneath dull brown, with the base broadly white, especially along the inner margin, and the white transverse spot beyond the cell larger than on the upper surface. Secondaries white, with the outer margin very broadly black, especially at the apex; underneath, the marginal band is dull brown. Body brown; palpi and fore coxæ reddish brown.

Expanse 38 millim. 
Charilina amabilis.

Noctua amabilis, Dru. Ill. Ex. Ent. ii. t. 13. f. 3.

Fam. CH A L C O S I D

Pseudopontia paradoxa.

Globiceps paradoxa, Feld. Pet. nouv. Ent. no. 8.

Fam. T H Y M A R I D E.

Pedoptila nemopteridia.

Pedoptila nemopteridia, Butl. Ann. Nat. Hist. (5) xv. p. 341.

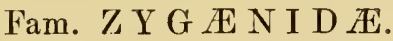

Subfam. ZYGENINEE.

Syntomis cerbera.

Sphinx cerbera, Linn. Mus. Ulr. p. 363.

Syntomis touvasina.

Syntomis touvasina, Butl. Journ. Linn. Soc. Lond., Zool. xii. p. 348.

Syntomis divalis, sp. nov. (Plate I. fig. 2.)

Primaries above black; at the base a large crimson spot; about the middle three hyaline spots, the largest being in the cell, and the next below it being the smallest; the anterior and posterior hyaline spots are followed by a round crimson spot, beyond which are three smaller hyaline spots followed by a subapical crimson band. Secondaries above black, with the costal margin yellowish. Underneath, the wings are dull black, with the base of the primaries and the costal margin of the secondaries yellowish. Antennæ black, with white tips. Frons yellow. Collar black, with two yellow spots. Thorax black, with a dorsal reddish line and a lateral red 
spot. Abdomen above crimson, with a black trausvcrse band on each segment. Underneath, the body is ycllowish, the legs outwardly streaked with brown.

Expanse 34 millim.

\section{Subfam. THYRETIN EE.}

Thyretes caffra.

Thyretes caffra, Wallengr. Wien. Ent. Mon. vii. p. 138.

Eressa bivittata.

Syntomis bivittata, Walk. Cat. Lep. Het. B. M. xxxi. p. 66 .

Saluinca aurifrons.

Saluinca aurifrons, Walk. Cat. Lep. Het. B. M. xxxi. p. 109.

\section{Subfam. EUCHROMIIN EE.}

Euchromia leonis.

Euchromia leonis, Butl. Journ. Linn. Soc. Lond., Zool. xii. p. 383.

Euchromia fulvida.

Euchromia fulvida, Butl. Trans. Ent. Soc. Lond. 1888, p. 112 , t. 4 . f. 5 .

Larva feeds upon sweet potato (Batatas edulis). It has been noticed fceding at mid-day, in the full glare of the sun. All the spccies of this family are fond of flying about gardenhedges, preferably those of Lantana. They are to be found sparingly all the year round, but appear in greatcr numbers in August, towards the cessation of the heavy rains. Period of pupation about 12 days. ( $\dot{W} . G . C$.)

Fam. A R C T I I D A.

Subfam. CHARIDEINE.

Charidea vicaria.

Euchronia vicaria, Walk. Cat. Lep. Het. B. M. i. p. 207. 


\section{Subfam. PHEGOPTERIN E.}

Anace burra, sp. nov. (Platc I. fig. 6.)

Primaries and body pinkish fawn-colour. Secondarics paler, with only the extreme margins darker. Antennæ dark brown; tarsi brown.

Expanse 31 millim.

Metarctia erubescens.

Metarctia erubescens, Walk. Cat. Lep. Het. B. M. xxxi. p. 315.

Casphalia picta, sp. nov. (Plate II. fig. 6.)

Primaries with the basal third yellow, except a small black space at the base itself; the entire costa and outer portion of the wing black; a subapical oblique yellow spot. Secondaries orange; the outer margin broadly black; a small round black spot beyond the cell. Head and collar orange. Thorax brown. Abdomen orange; the anal segment black.

Expanse 32 millim.

\section{Subfam. SPILOSOMATIN}

Alpenus maculosus.

Bombyx maculosa, Stoll, Pap. Ex. iv. t. 370, B.

Fam. L I T H O S I I D Æ.

Utetheisa pulchella.

Tinea pulchella, Linn. Syst. Nat. i. p. 534.

Argina leonina.

Deiopeia leonina, Walk. Cat. Lep. Het. B. M. xxxi. p. 262.

Argina cingulifera?

Deiopeia cingulifera, Walk. Cat. Lep. Het. B. M. ii. p. 569. 


\section{Fam. H Y P S I D A.}

Pseudhypsa speciosa.

Noctua speciosa, Dru. Ill. Ex. Ent. ii. t. 5. f. 2.

Caryatis syntomina.

Caryatis syntomina, Butl. Ann. Nat. Hist. (5) ii. p. 456.

Godasa maculatrix.

Godasa maculatrix, Walk. Cat. Lep. Het. B. M. xxxi. p. 271.

\section{Fam. N Y C T E M E R I D AE.}

Aletis flammea, sp. nov. (Plate II. fig. 2.)

Primaries above and below black, crossed just beyond the middle by an oblique, broad white band, from the costal vein to nearly the inner angle. Secondaries fiery red, yellowish along the costal margin; the base shaded with blackish scales, and a broad black outer margin, becoming quite narrow at the anal angle. Head red; a black spot on the frons. Collar red, with two black spots. Tegulæ red, with a black streak. Abdomen above red; a subdorsal row of black spots : underneath yellow, with a lateral row of black spots. Legs brown outwardly, ycllowish inwardly; fore coxæ red, with a small black spot.

Expanse 50 millim.

Pitthea continua.

Pitthea continua, Walk. Cat. Lep. Het. B. M. ii. p. 463.

Nyctemera perspicua.

Nyctemera perspicua, Walk. Cat. Lep. Het. B. M. ii. p. 398.

Nyctemera apicalis.

Nyctemera apicalis, Walk. Cat. Lep. Het. B. M. ii. p. 395. 
Amnemopsyche famula.

Bombyx famula, Dru. Ill. Ex. Ent. ii. t. 11. f. 3.

Amnemopsyche gracilis.

Amnemopsyche gracilis, M̈̈schl. Abhandl. Senckenb. Ges. xv. p. 73. f. 1 .

0trœda occidentis.

Otrœela occidentis, Walk. Cat. Lep. Het. B. M. ii. p. 403.

0trœda nerina.

Bombyx nerina, Dru. Ill. Ex. Ent. iii. t. 5. f. 1.

Fam. L I P A R I D A.

Geodena quadrigutta.

Geodena quadrigutta, Walk. Cat. Lep. Het. B. M. vii. p. 1691.

Eloria divisa.

Eloria divisa, Walk. Cat. Lep. Het. B. M. iv. p. 815.

Redoa laba, sp. nov. (Plate I. fig. 4.)

Entirely snow-white, except the palpi, frons, tarsi, and fore coxæ, which are orange. In the female the costal margin of the primaries is narrowly yellow.

Expanse, ơ 33 millim., $q 42$ millim.

Antiphella crocicollis.

Liparis crocicollis, Herr.-Schäff. Aussereur. Schmett. i. f. 110.

Cypra eleuteria.

Bombyx eleuteria, Stoll, Suppl. Cram. t. 36. f. 13.

Crorema mentiens.

Crorema mentiens, Walk. Cat. Lep. Het. B. M. iv. p. 811. 
Artaxa modesta, sp. nov. (Plate II. fig. 4.)

Entirely pale yellow.

Expanse 25 millim.

Chrysopsyche mirifica.

Chorotriche mirifica, Butl. Ann. Nat. Hist. (5) ii. p. 458.

Utidava? citana, sp. nov. (Plate I. fig. 10.)

Primaries above pale buff; the costal margin to nearly the apex very broadly blackish brown, this colour occupying nearly the entirc cell, and enclosing at the end of the cell a cluster of much darker scales; the inner margin broadly shaded with light brown; the outer margin from the apex broadly blackish brown, this shade being inwardly dentate and crossed by a marginal row of small buff spots, outwardly edged with blackish scales. Secondaries above yellowish white. Underneath yellowish white, the costal margin of the secondaries and the entire primaries shaded with brown. Head and thorax dark brown. Abdomen lighter brown.

Expanse 24 millim.

Lælia fracta, sp. nov. (Plate I. fig. 12.)

Primaries above light buff, finely speckled with dark scales; a dark shade cxtcnding from the base, through the cell, to almost the outer margin; on the posterior two thirds of the wing a marginal oblique row of small dark spots; the fringe altcrnately buff and grey. Secondarics whitish. Underneath, the wings are dirty white. Body greyish.

Expanse 21 millim.

Lælia rosea, sp. nov. (Plate I. fig. 5.)

Primaries above pink, thinly speckled with dark scales; a curved marginal row of black points. Secondaries pinkish white. Body pinkish.

Expanse 22 millim.

Aroa danva, sp. nov. (Plate I. fig. 3.)

Male. Primaries above brown, darker along the costal margin, beyond the cell, and at the apex, exeept a light 
shade on the costal margin at about two thirds from the base; some greenish scales at the base of the costal vein, below the subcostal vein, and at the inner angle; an inner, outer, and submarginal transverse irregular dark line, in part very indistinet; the fringe alternately light and dark browu: underneath yellow; at the base of the inner margin a broarl brownish space; the apical third of the wing brownish, faintly mottled with yellow. Secondaries above brown, dirkest along the costal margin; an orange band starting near the base, and gradually widening towards the middle of the outcr margin: underneath yellowish, shaded with brown; a large dark brown spaee at the apex; a transverse wavy brown line not reaching the inner margin, and a dark lunular mark in the cell. Body above dark brown, underneath light brown.

Expanse 39 millim.

Orgyia ticana, sp. nov. (Plate I. fig. 11.)

Primaries above dark brown; along the inner margin and at the apex yellowish; a basal, median, and outer transverse angular dark line, partly bordered with yellowish where approaching the lighter shades on the wing; at the end of the cell two short dark transverse streaks : underneath light brown, darker in the disc; an outer transverse nearly straight brown line. Secondaries above greyish brown: underneatl light brown; a small brown ring in the cell and two transverse brownish lines, the outer one being indistinct and broken. Body brown.

Expansc 20 millim.

Dasychira acrisia.

Deiopeia (?) acrisia, Plötz, Stett. ent. Zeit. xli. p. 83.

Fam. L I M A C O D I D E.

Heterolepis plötzi, sp. nov. (Plate II. fig. 1.)

Primaries above with the costal margin and outer third of the wing light brown; at the apex a terminal velvety brown line, preceder by a broad but short dark brown mark; other- 
wise violaceous brown, with a black transverse basal streak, and beyond this a more conspicuous transversc wavy black line from the cell to the inner margin; at the end of the cell a black spot. Secondaries above grcyish brown; all the fringes very long, yellowish brown. Underneatl, the wings are yellowish brown, sprinkled with darker scales; the outer margins indistinctly outlined with dark scales. Body light brown; the anterior portion of the thorax, two clusters of scales dorsally at the base of the abdomen, and the fore eoxæe dark velvety brown.

Expanse 20 millim.

Allied to Heterolepis leprosa, Felder.

Miresa syrtis, sp. nov. (Plate II. fig. 3.)

Primaries above brown, thinly speckled with darker scales, cspecially on the veins; a dark transversc line, slightly curved, from the costal margin at two thirds from the base to the middle of the inner margin; a similar, nearly straight submarginal line. Secondarics brown, with a few dark scales on the outer margin near the apex. Underneath, the wings arc uniformly brown. Body brown.

Expanse 19 millim.

Allicd to Miresa hilda, Druce.

Fam. NO T O D O N T I D E.

Rigema ornata.

Rigema ornata, Walk. Cat. Lep. Het. B. M. xxxii. p. 437.

Anthena simplex.

Anthena simplex, Walk. Cat. Lep. Het. B. M. iii. p. 687.

Fam. B O M B Y C I D A.

Naroma signifera.

Naroma signifera, Walk. Cat. Lep. Het. B. M. vii. p. 1744 . 
Fam. D R E P A N U L I D E.

Plegapteryx anomalus.

Plegapteryx anomalus, Herr.-Schäff. Ausscrcur. Schmett. i. ff. $46.2,463$.

Fam. S A T U R N I I D E.

Bunæa eblis.

Bunca eblis, Streck. Lep. p. 121, t. 14. f. 9.

Bunæa jamesoni.

Bunca jamesoni, Druce, Jameson, Story of Rear Column, p. 448.

Imbrasia obscura.

Gonimbrasia obscura, Butl. Ann. Nat. Hist. (5) ii. p. 462.

Antheræa arata.

Saturnia arata, Westw. Proc. Zool. Soc. Lond. 1849, p. 41, t. 7. f. 2.

Antheræa dione.

Bombyx dione, Fabr. Ent. Syst. iii. (1) p. 410.

Eudæmonia brachyura.

Attacus brachyura, Dru. Ill. Ex. Ent. iii. t. 29. f. 1.

Eudæmonia argiphontes.

Eudamonia argiphontes, Kirby, Trans. Ent. Soc. Lond. 1877 , p. 20.

Bolocera smilax.

Saturnia smilax, Westw. Proc. Zool. Soc. Lond. 1849, p. 59, n. 31 . 


\section{Fam. L A S I O C A M P I D A.}

Stibolepis cunina.

Attacus cunina, Cram. Pap. Exot. iii. t. 257, G.

Stibolepis odites, sp. nov. (Plate I. fig. 9.)

Wings above snowy white; on the primaries the outer portion of the veins finely outlined with brown. Underneath, the costal and extreme outer margins, also the veins on the secondaries, yellowish. Head and collar orange. Thorax white. Abdomen yellowish, with indistinct transverse greyish shades.

Expanse 48 millim.

\section{Homochroa? orphne, sp. nov. (Plate I. fig. 7.)}

Male. Primaries above greyish white; some velvety brown marks at the base; at the end of the cell, which is very short, an obliquc black spot containing a whitish line; two median, outwardly curved, lunular transverse brownish shades, followed by other similar but more indistinct shades; the apex brownish, forming a dark patch on the outer margin below the apex, and an oblique dark shade on the costal margin; fringe brown, with longitudinal white streaks. Secondaries above yellowish white; the veins finely brown towards the outer margin; some long orange scales towards the base; some velvety-brown markings along the inner margin; two transverse angular brown lines from the costal to the inner margin. Underneath creamy white; the veins and extreme outer margin brown; the costal margin of the primaries orange, and on the same wings a dark shade below the apex on the outer margin; on the secondaries the markings of the upper surface are repeated, but the transverse lines are followed by some submarginal lunular marks. Head and collar brown. Thorax mottled brown and white. Abdomen dorsally brownish, laterally white, underneath orange.

Expanse 62 millim. 
Jana eurymas.

Jana eurymas, Herr.-Schäff. Aussereur. Schmett. f. 98.

Jana strigina.

Lasiocampa strigina, Westw. Proc. Zool. Soc. Lond. 1849, p. 37.

Lichenopteryx fulvia.

Lichenopteryx fulvia, Drucc, Proc. Zool. Soc. Lond. 1886, p. 411.

Stenoglene rudis.

Lasiocampa rudis, Walk. Cat. Lep. Het. B. M. xxxii. p. 561.

Dendrolimus bipars.

Lebeda bipars, Walk. Cat. Lep. Het. B. M. vi. p. 1455 .

Dendrolimus ferruginea.

Pachypasa ferruginea, Feld. Reise d. Novara, t. 85. f. I.

Dendrolimus basalis.

Megasoma basale, Walk. Cat. Lep. Het. B. M. vi. p. $1+48$.

Gastropacha gerstaeckeri.

Gastropacha yerstaeckeri, Dewitz, Verh. Leop.-Car. Akad. xlii. p. 74 , t. 1 . f. 6 .

Lasiocampa heres, sp. nov. (Plate I. fig. 8.)।

Primaries above olivaceous, shaded with brown, the middle of the inner margin being the palest; a basal and an outer transverse darker line, the former slightly undulating, the latter forming an angle beyond the cell and reaching the inner margin in its centre. Secondaries olivaceous brown, paler on the costal margin; an ill-defincd blackish marginal shade; a transverse linc starting from the costal margin and only noticeable on the lighter portion of the wing. Underneath olivaceous brown, with a transverse undulating darker shade, chiefly noticeable on the secondaries. Body olivaceous brown; the head and palpi brown.

Expanse 5:2 millim. 
Lasiocampa mæra. (Plate II. fig. 5.)

Primaries above greenish yellow, shaded with reddish brown along the costal margin and below the cell; a broarl submarginal transverse shade of a dull brown, this shade being very irregular exteriorly; a basal and a median transverse reddish-brown line, and a small spot at the end of the cell of a similar colour. Secondaries above dark brown, shaded with reddish along the costal margin. Underneath, the wings are reddish brown, with the inner margin of the secondaries broadly dark brown. Head, thorax, and anal segment ycllowish green. Abdomen brown; lighter underneath.

Expanse 44 millim.

Fam. P I N A R I D E.

Cyrtogone herilia.

Saturnia herilia, Westw. Proc. Zool. Soc. Lond. 1849, p. 57, t. 11 . f. 3 .

Cyrtogone nenia.

Saturnia nenia, Westw. Proc. Zool. Soc. Lond. 1849, p. 57, t. 9. f. 3 .

Gonometa cassandra.

Gonometa cassandra, Druce, Proc. Zool. Soc. Lond. 1887, p. 681.

Gonometa matuta, sp. nov. (Platc II. fig. 8.)

Female. Primaries above greyish brown; a black point at the end of the cell; two median transverse wavy grey lines; a submarginal irregular transverse greyish shade. Secondarics yellowish; the custal margin greyish brown. Underneath, all the wings brownish yellow. Head and thorax greyish brown. Abdomen yellowish.

Expanse 78 millim. 
Fam. Z E U Z E R I D A.

Zeuzera boisduvalii.

Zeuzera boisduvalii, Herr.-Schäff. Aussereur. Schmctt. i. f. 167 .

\section{Cossus toluminus.}

Cossus toluminus, Druce, Proc. Zool. Soc. Lond. 1887, p. 684 .

Fam. N O C T U I D E.

Opigena accipiter, sp. nov. (Plate II. fig. 7.)

Primaries above brown; the basal third blackish, crossed near the base and outwardly shaded by two transversc greyish lines; some grcyish and vclvety brown scales at the end of the cell; an irregular submarginal dark shade, on eithcr sidc of which are some greyish scales. Secondaries light brown; the veins somewhat darker; an indistinct transverse whitish shade. Underneatl, the wings are dirty brown, with a median and a submarginal transverse dark shadc; a dark spot on the middle of the costal margin of the primarics, and a still larger spot on the costal margin of the secondaries nearer the base. Body dark grey.

Expanse 43 millim.

Ochropleura talda, sp. nov. (Plate III. fig. 1.)

Primaries dark grey, lighter on the outer margin; the orbicular and reniform very indistinct; between the two somc velvety black scales, and beyond the reniform somc similar scales; along the outcr margin some dark longitudinal streaks between the veins. Secondarics white; the fringe at the apex smoky. Body grcy; two dark brown spots on the collar.

Expanse 25 millim.

Perigea africana, sp. nov. (Plate II. fig. 10.)

Primarics brown; at the basc of the costa a whitc spot and another below it; just before the orbicular a white 
wavy mark on the costa, and a round white spot below the median vein; the orbicular surrounded by four whitc points; the reniform fawn-colour, surrounded and broken by white spots; a white spot on the costa above the reniform; between this and a subapical white spot a few white points on the costa; a white spot near the middle of the outer margin, and a similar spot on the inner margin near the angle; beyond the reniform some indistinct transverse lines. Secondaries brownish. Body brown.

Expanse 30 millim.

Very similar to Perigea stelligera, Guenée.

Spodoptera mauritia.

Hadena mauritia, Boisd. Faun. Ent. Mad. 92, 3. pl. 13. f. 9.

Glottula pancratii.

Noctua pancratii, Cyrillo, Ent. Neapol. pl. 12. f. 4.

Euthisanotia florifera.

Polytela florifera, Walk. Cat. Lep. Het. B. M. xv. p. 1666.

Meliana bertha, sp. nov. (Plate III. fig. 3.)

Primaries above buff, thickly speckled with black scales; beyond the cell a conspicuous black spot, preceded by a much smaller onc, and followed by a transverse row of black points; on the cxtreme margin a row of black points; a dark shade from the large black spot to the apex : underueath whitish buff, with a black spot on the costal margin at four fifths from the basc. Secondaries whitish, slightly smoky on the outcr margin. Body buff.

Expanse 25 millim.

Curubasa lanceolata.

Laria lanceolata, Walk. Cat. Lep. Het. B. M. xxxiii. p. 767 .

Episparis penetrata.

Episparis penetrata, Walk. Cat. Lep. Het. B. M. x. p. 476. 
Xanthodes graellsii.

Acontia graellsii, Feisth. Ann. Soc. Ent. Fr. vi. p. 300, pl. 12. f. 3 .

Acontia camilla.

Xanthodes camilla, Druce, Proc. Zool. Soc. Lond. 1887, p. 686.

Leocyma polla, sp. nov. (Plate II. fig. 11.)

Primaries silvery whitish; a broad irregular median transverse brownish band, and a submarginal narrow brown shade, widening at the costal margin; the extreme margin finely brown; fringe greyish. Secondaries light brown. Head and collar yellow. Thorax and abdomen whitish brown.

Expanse 22 millim.

Leocyma pollusca, sp. nov. (Plate II. fig. 12.)

Primaries light brown, slightly tinged with violaceous; two fine and straight transverse brown lines, the first oblique, the second beyond the middle of the wing. Secondaries dark browu; the extreme margin paler. Body brown.

Expanse 27 millim.

Leocyma fustina, sp. nov. (Plate II. fig. 9.)

Primaries above rich brown; the orbicular represented by a white point; the reniform yellowish, containing a white point; on the posterior half of the wing a submarginal broad yellowish shade; on the extreme outer margin a row of black points outwardly shaded with yellowish. Secondaries dull brown; the fringe lighter. Underneath light brown, with an outer transverse brownish line; black points on the extreme outer margins; a black discal spot on the secondaries.

Expanse 38 millim.

Earias fervida.

Earias fervida, Walk. Cat. Lep. Het. B. M. xxxv. p. 1774.

Xanthoptera colla, sp. nov. (Plate III. fig. 6.)

Primaries light grey; the costal margin palcr; at the apex 
a small blaek mark inwardly shaded with white seales; the fringe yellowish. Seeondaries yellowish white. Underneath, the wings are yellowish, the dise of the primaries shaded with brown. Head and eollar orange. Thorax and abdomen whitish grey.

Expanse 18 millim.

Xanthoptera allecta, sp. nov. (Plate III. fig. 4.)

Primaries with the basal half yellow and the outer half violaeeous brown; at the base of the inner margin a blackish spot and a basal transverse wavy line; in the eell a blaek point, above which, on the eostal margin, is a brown spot; the middle third of the outer half oeeupied by a transverse wavy line of lighter brown. Seeondaries dull brown; the fringe reddish. Head and thorax yellow; the abdomen brownish.

Expanse 23 millim.

\section{Tarache pyralina.}

Acontia pyralina, Walk. Cat. Lep. Het. B. M. xii. p. 789.

Tarache perta, sp. nov. (Plate III. fig. 2.)

Primaries above snowy white; at the base some brownish marks on the eosta; a broad median transverse brown band widest on the inner margin; the outer margin broadly shaded with brown, espeeially towards the apex, this shade advaneing inwardly towards the eell. Seeondaries grey. Head and thorax white; abdomen yellowish grey.

Expanse 15 millim.

Gonitis fulvida.

Anomis fulvida, Guen. Noet. ii. p. 397.

Gonitis leona, sp. nov. (Plate III. fig. 10.)

Primaries above brown, tinged with violaeeous; the apex slightly paler; the basal line distinet, inwardly shaded with greyish seales near the eostal margin; the outer line exteriorly shaded with dark brown; a eonspieuous yellow spot below the median vein at about its middle; the fringe blaekish, with its extremity between the veins shaded with 
yellowish white. Secondaries dull brown. Underneath, the primaries have the disc blackish, the costal and outer margins pale, and the apex reddish. The secondaries are reddish, with an outer wavy line.

Expanse 35 millim.

Birtha talusina, sp. nov. (Plate III. fig. 12.)

Primaries with the base dark violaceous brown from the costal margin at one fourth to the middle of the inner margin, this space being crossed by a light buff line, which forms a sharp angle on the subcostal vein; beyond this the wing is pale buff, except a large triangular dark space on the costal margin just beyond the middle, and a smaller dark space on the same margin before the apex; a small velvety spot in the cell, in an oblique line with a smaller spot on the costal margin; beyond the cell a small dark space; a wavy median transverse line and an outcr straight line to the inner angle. Secondaries light brown. Body brown.

Expanse 30 millim.

Allied to B. insulata, Walk.

Aedia discistriga.

Anophia discistriga, Walk. Cat. Lep. Het. B, M. xiii. p. 1128.

Piala basipunctum.

Piala basipunctum, Walk. Cat. Lep. Het. B. M. xv. p. 1766.

Bareia incidens.

Bareia incidens, Walk. Cat. Lep. Het. B. M. xv. p. 1840.

Ophideres fullonica.

Phalæna-Noctua fullonica, Linn. Syst. Nat. p. 812.

Argadesa materna.

Phalana-Noctua materna, Liun. Syst. Nat. ii. p. 810.

Halustria intricatus.

Halustria intricatus, Butler. 
Trisula magnifica, sp. nov. (Plate III. fig. 8.)

Primaries light grey, mottled with pale reddish brown below the apex from the costal to the outer margin, close to the inner angle, and on the reniform; a broad velvety black basal transverse band; at two thirds from the base on the costal margin a triangular black spot, from which starts an outer irregular and indistinct line. Secondaries white, with the outer margin broadly black. Underneath, the primaries are dull brown, except a white space occupying two thirds of the inner margin, and a transverse broad whitish band; a discal spot on the secondaries below. Head and thorax reddish grey. Abdomen whitish; a quadrate black dorsal spot at the base.

Expanse $6 \tilde{\text { millim. }}$

Miniodes discolor.

Miniodes discolor, Guen. Noct. iii. p. 119.

Patula macrops.

Phalana-Noctua macrops, Linn. Syst. Nat. p. 225.

Cyligramma limacina.

Cyligramma limacina, Guér. Règn. Anim., Ins. pl. 89. f. 2.

Cyligramma fluctuosa.

Phalana fluctuosa, Dru. Ill. Ex. Ent. ii. pl. 14. f. 1.

Maxula capensis.

Hypopyra capensis, Herr.-Schäff. Aussereur. Schmett. ff. 121, 122.

Ophiodes finifascia.

Nephelodes finifascia, Walk. Cat. Lep. Het. B. M. xv. p. 1676.

Ericeia inangulata.

Hulodes inangulata, Guen. Noct. iii. p. 210.

Ophisma klugii.

Ophiusa klugii, Boisd. Faun. Ent. Mad. p. 103. 
Ophisma illustrata.

Achaa illustrata, Walk. Cat. Lep. Het. B. M. xiv. p. 1392. 0phisma lienardi.

Ophiusa lienardi, Boisd. Faun. Ent. Mad. p. 102, pl. 15. f. 5.

Ophisma exhibens.

Ophisma exhibens, Walk. Cat. Lep. Het. B. M. xiv. p. 1388.

Ophisma mormoides.

Achaa mormoides, Walk. Cat. Lep. Het. B. M. xiv. p. 1393.

Achæa leona.

Achrea leona, Feld. Reise d. Nov. pl. cxvi. f. 13.

Ophiusa allardi.

Ophiusa allardi, Oberth. Etud. d'Ent. iii. p. 35, t. 2. f. 6.

0phiusa angularis.

Ophiusa angularis, Boisd. Faun. Ent. Mad. p. 103, t. 13. f. 2 .

Trigonodes hyppasia.

Phalana-Noctua hyppasia, Cram. Pap. Exot. iii. t. 250. f. E.

Audea bipunctata.

Audea bipunctata, Walk. Cat. Lep. Het. B. M. xii. p. 1135.

Remigia repanda.

Noctua repanda, Fabr. Ent. Syst. iii. 2. p. 49.

Remigia mayeri.

Ophiusa mayeri, Boisd. Faum. Ent. Mad. p. 104.

Remigia lituraria.

Alamis lituraria, Saalm. Lep. v. Mad. p. 419.

Focilla docta, sp. nov. (Plate III. fig. 15.)

Primarics above reddish brown; a transverse line from 
near the apex to the inner margin, outwardly shaded with greyish; at the end of the eell an inwardly eurved hyaline streak: underneath greyish, with a basal, median, and marginal reddish shade; at the apex a reddish-brown spot. Seeondaries above reddish brown; a brighter transverse band and an irregular hyaline mark at the end of the eell : underneath reddish, with a straight transverse grey line. Body reddish browi.

Expanse 30 millim.

Azazia rubricans.

Ophiusa rubricans, Boisd. Faune Lép. Mad. p. 106, t. 16. f. 1 .

Calobochyla silona, sp. nov. (Plate III. fig. 5.)

Primaries brown, shaded with red along the eostal and outer margins; from the apex to the middle of the inner margin an indistinet dull brown shade; a submarginal row of minute blaek spots. Seeondaries dull brown, with the fringe reddish. Underneath, the wings are reddish, with the dise of the primaries brown, and the inner margin of the seeondaries whitish. Body brown. Legs reddish.

Expanse 25 millim.

Hypena obacervalis.

Hypena obacervalis, Walk. Cat. Lep. Het. B. M. xvi. p. 53.

Hypena lividalis.

Pyralis lividalis, Hübn. Eur. Sehmett. v. f. 11. 186.

Hypena saltalis, sp. nov. (Plate III. fig. 14.)

Primaries above greyish brown; two velvety blaek spots at a third from the base, one above, the other below the median vein; an indistinet outer brown line. Seeondaries greyish brown. Underneath lighter, espeeially along the inuer margin of the seeondaries. Body greyish brown.

Expanse 21 millim.

Hypena? ducalis, sp. nov. (Plate III. fig. 13.)

Primaries brownish, with nearly the entire basal half exeept 
the costa bright orangc. Seeondarics orange, with the outer margin broadly blackish. Head, collar, and anterior half of the thorax brown; posterior half of the thorax and first abdominal segments orange; the rest of the abdomen brown.

Expanse 28 millim.

Sophronia capalis.

Sophronia capalis, Walk. Cat. Lep. Het. B. M. xvi. p. 9J.

Herminia mascusalis.

Herminia mascusalis, Walk. Cat. Lep. Het. B. M. xvi. p. 112.

Hydrillodes? janalis, sp. nov. (Plate-III. fig. 11.)

Primaries above rich brown, crossed from the eostal to the inner margin by two snowy-white irregular lines; near the apex some very indistinct marginal white seales : underneath dull brown, with the eostal outer margins greyish; an indistinet outer whitish shade. Sccondaries above blaekish brown: underneath grey; a white discal spot and two outer wavy brown lines. Body brown above, greyish white underneath.

Expanse 20 millim.

Dragana pansalis.

Dragana pansalis, Walk. Cat. Lep. Het. B. M. xvi. p. 200.

Marimatha duplicalis.

Marimatha duplicalis, Walk. Cat. Lep. Het. B. M. xxxiv. p. 1205.

Fam. G E O M E T R I D A.

Zamarada transvisaria.

Epione transvisaria, Guen. Uran. ct Phalén. ix. p. 98.

Zamarada reflexaria.

Comibana reflexaria, Walk. Cat. Lep. Hct. B. M. xxvi. p. 1565. 
Racotis squalida.

Ophthalmodes squalida, Butl. Ann. Nat. Hist. (5) ii. p. 465 (1878).

Pingasa ruginaria.

Hypochroma ruginaria, Guen. Uran. et Phalén. ix. p. 278.

Microloxia latilineata.

Geometra latilineata, Walk. Cat. Lep. Het. B. M. xxxv. p. 1605 .

Thalassodes congrua.

Geometra congrua, Walk. Desc. Het. Lep. from Congo, p. 47 .

Pareumelea perlimbata.

Palyas perlimbata, Guen. Uran. et Phalén. ix. p. 396.

Rhamidava fulvata.

Phalcena fulvata, Dru. Ill. Ex. Ent. iii. t. 21. f. 4.

Rhamidava amplissimata.

Acidalia amplissimata, Walk. Cat. Lep. Het. B. M. xxvi. p. 1614 .

Timana sodaliata.

Rhamidava sodaliata, Walk. Cat. Lep. Het. B. M. xxvi. p. 1568.

Anisodes leonaria.

Ephyra leonaria, Walk. Cat. Lep. Het. B. M. xxii. p. 635.

Gnamptoloma neptunaria.

Timandra neptunaria, Guen. Uran. et Phalén. x. p. 3, pl. 18. f. 5 .

Idœa remotata.

Acidalia remotata, Guen. Uran. et Phalén. ix. p. 458.

Idœa lactaria.

Acidaha lactaria, Walk. Cat. Lep. Het. B. M. xxii. p. 744 . 
Idcea cleoraria.

Acidalia cleoraria, Walk. Cat. Lep. Het. B. M. xxiii. p. 792.

Rambara melagonata.

Zanclopteryx melagonata, Walk. Cat. Lep. Het. B. M. xxvi. p. 1619.

Acropteris erycinaria.

Micronia erycinaria, Guen. Uran. et Phalén. x. p. 30.

Acropteris tenella.

Micronia tenella, Walk. Desc. Het. Lep. from Congo, p. 53.

Dirades theclata.

Erosia theclata, Guen. Uran. et Phalén. x. p. 36.

Tephrina exfusaria.

Aspilates exfusaria, Walk. Cat. Lep. Het. B. M. xxvi. p. 1683.

Leucetœra simpliciata.

Cidaria simpliciata, Walk. Cat. Lep. Het. B. M. xxv. p. 1422 .

Fam. P Y R A L I D E.

Pachynoa phialusalis.

Botys phialusalis, Walk. Cat. Lep. Het. B. M. xix. p. 991.

Cirrochrista saltusalis, sp. nov. (Plate III. fig. 7.)

Primaries above white; the basal third of the costa orange, this orange continuing in an oblique line to the inner margin; beyond the cell a broad transverse orange line, posteriorly bifureating to the middle of the inner margin and to the inner angle; an indistinet subapieal transverse orange line; 
on the extreme margin a series of black marks; the fringe orange. Secondaries silvery whitc; a row of black points on the extreme margin. Body white; an orange transverse band on the third abdominal segment; the anus golden, circled with black.

Expanse 24 millim.

Pharazia otreusalis.

Botys otreusalis, Walk. Cat. Lep. Het. B. M. xviii. p. 637.

Acharana cynaralis?

Botys cynaralis, Walk. Cat. Lep. Het. B. M. xviii. p. 672.

Acharana verminalis.

Botys verminalis, Guenée, Delt. et Pyral. p. 348.

Chrysotidiris hirtusalis.

Botys hirtusalis, Walk. Cat. Lep. Hct. B. M. xviii. p. 642.

Pygospila tyres.

Phalana-Pyralis tyres, Cram. Pap. Exot. iii. t. 263, C.

Margaronia baldersalis.

Margaronia baldersalis, Walk. Cat. Lep. Het. B. M. xviii. p. 527.

Margaronia ocellata.

Margaronia ocellata, Warr.

Stemorrhages sericea.

Phalcena sericea, Dru. Ill. Ex. Ent. ii. pl. 6. f. 1.

Eudioptis indica.

Eudioptis indica, Saunders, Zool. ix. p. 3070.

Tobata elealis.

Tobata elealis, Walk. Cat. Lep. Het. B. M. xviii. p. 516.

Notarcha mysisalis.

Botys mysisalis, Walk. Cat. Lep. Het. B. M. xviii. p. 634. 
Haritala temeratalis.

Botys temeratalis, Zeller, Caff. p. 42.

Zebronia podalirialis.

Spilomela podalirialis, Guen. Delt. et Pyral. p. 281.

Coptobasis sarronalis.

Botys sarronalis, Walk. Cat. Lep. Het. B. M. xviii. p. 636.

Coptobasis leonalis, sp. nov. (Plate III. fig. 9.)

Primaries brownish black; a white spot in the cell, another above the middle of the inner margin; beyond the cell a short row of small contiguous spots to the costal margin. Secondaries brownish black, with an indistinct whitish transverse line. Underneath brown, with all the markings more distinct. Body blackish above, white underneath.

Expanse 24 millim.

Hymenea recurvalis.

Phalana recurvalis, Fabr. Ent. Syst. iii. 2. 237.

Hedylepta vulgalis.

Asopia vulgalis, Guen. Delt. et Pyral. p. 202.

Orphanostigma abruptalis.

Asopia abruptalis, Walk. Cat. Lep. Het. B. M. p. 371.

Bocchoris inspersalis.

Adiodes inspersalis, Zeller, Caff. p. 33.

Agrotera citrina.

Agrotera citrina, Warr.

Eurrhyparodes tricoloralis.

Diasemia tricoloralis, Zeller, Caff. p. 31.

Lepyrodes geometralis.

Lepyrodes geometralis, Guen. Delt. et Pyral. p. 278. 
Crochiphora testulatis.

Crochiphora testulalis, Hübn. Samml. Exot. Schmett. ff. 629,630 .

Cadarena sinuata.

Phalcena sinuata, Fabr. Ent. Syst. iii. p. 208.

Narasmia venilialis.

Asopia venilialis, Walk. Cat. Lep. Het. B. M. xvii. p. 373.

Dolichosticha trapezalis.

Salbia trapezalis, Guen. Delt. et Pyral. p. 200. 

PLA'E I.

Fig. l'age

1. Egocera leona . . . . . . . . . . 20

2. Syntomis divalis . . . . . . . . . . . 21

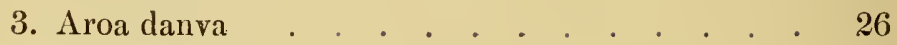

4. Redoa laba . . . . . . . . . . . . 25

5. Lælia rosea . . . . . . . . . . . . . 26

6. Anace burra . . . . . . . . . . . 23

7. Homochroa? orphnc . . . . . . . . . . 30

8. Lasiocampa lieres. . . . . . . . . . . 31

9. Stibolepis odites . . . . . . . . . . . 30

10. Utidava? citana . . . . . . . . . . . 26

11. Orgyia ticana . . . . . . . . . . . . 27

12. Laclia fracta . . . . . . . . . 26 

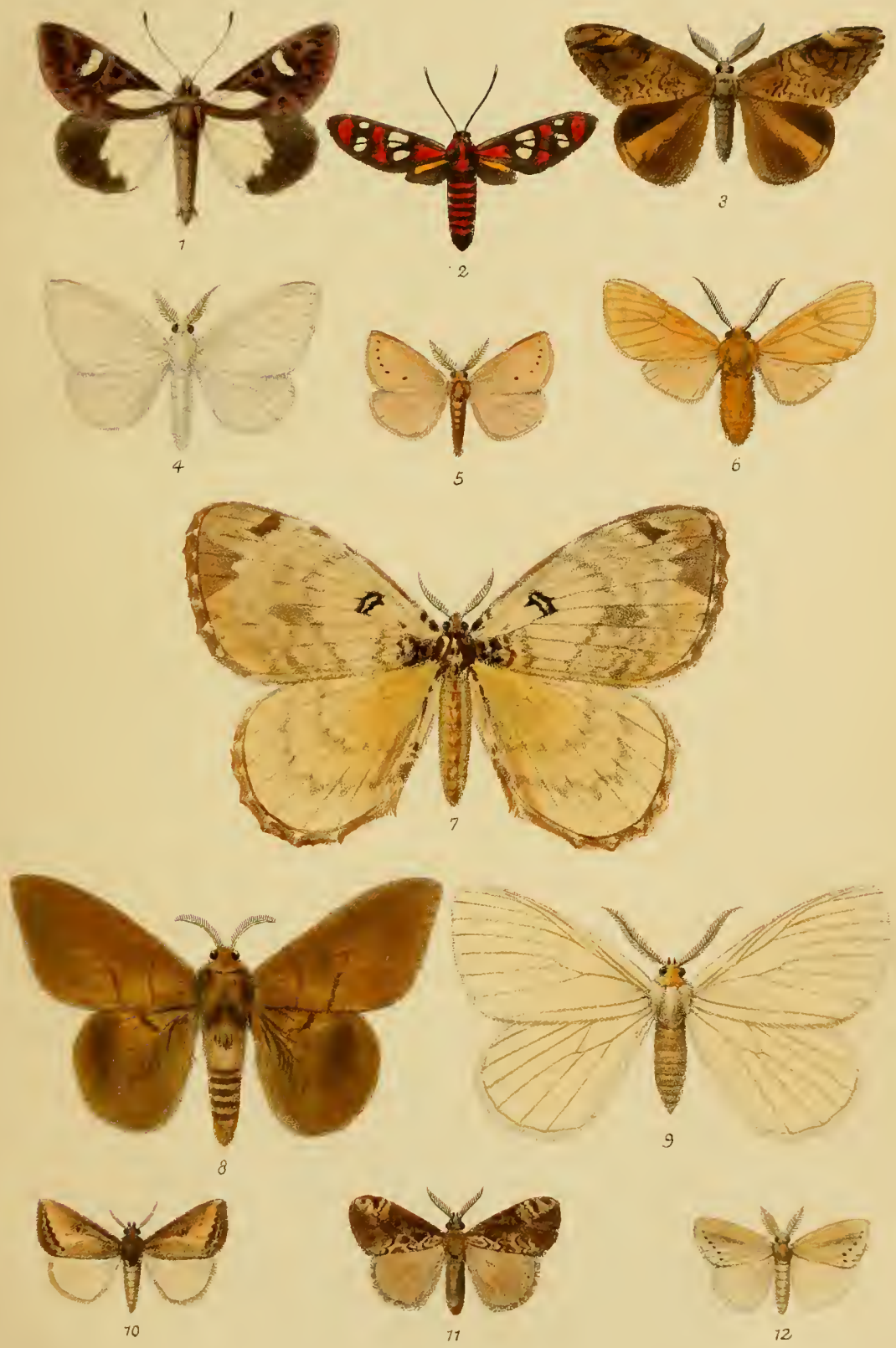

W.Purkis: lith

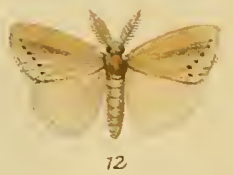





\section{PLA TE II.}

Fig. $\quad$ Page

1. Heterolepis plötzi . . . . . . . . . . . 27

2. Alctis flammea . . . . . . . . . . . 24

3. Miresa syrtis . . . . . . . . . . . . 28

4. Artaxa modesta . . . . . . . . . . . 26

5. Lasiocampa mæra . . . . . . . . . . 32

6. Casphalia picta . . . . . . . . . . . 23

7. Opigcna accipiter . . . . . . . . . . . 33

8. Gonometa matuta . . . . . . . . . 32

9. Leocyma fustina . . . . . . . . . . . 35

10. Perigea africana . . . . . . . . . . . 33

11. Leocyma polla . . . . . . . . . . . . 35

12. Leocyma pollusea . . . . . . . . . . . 35 

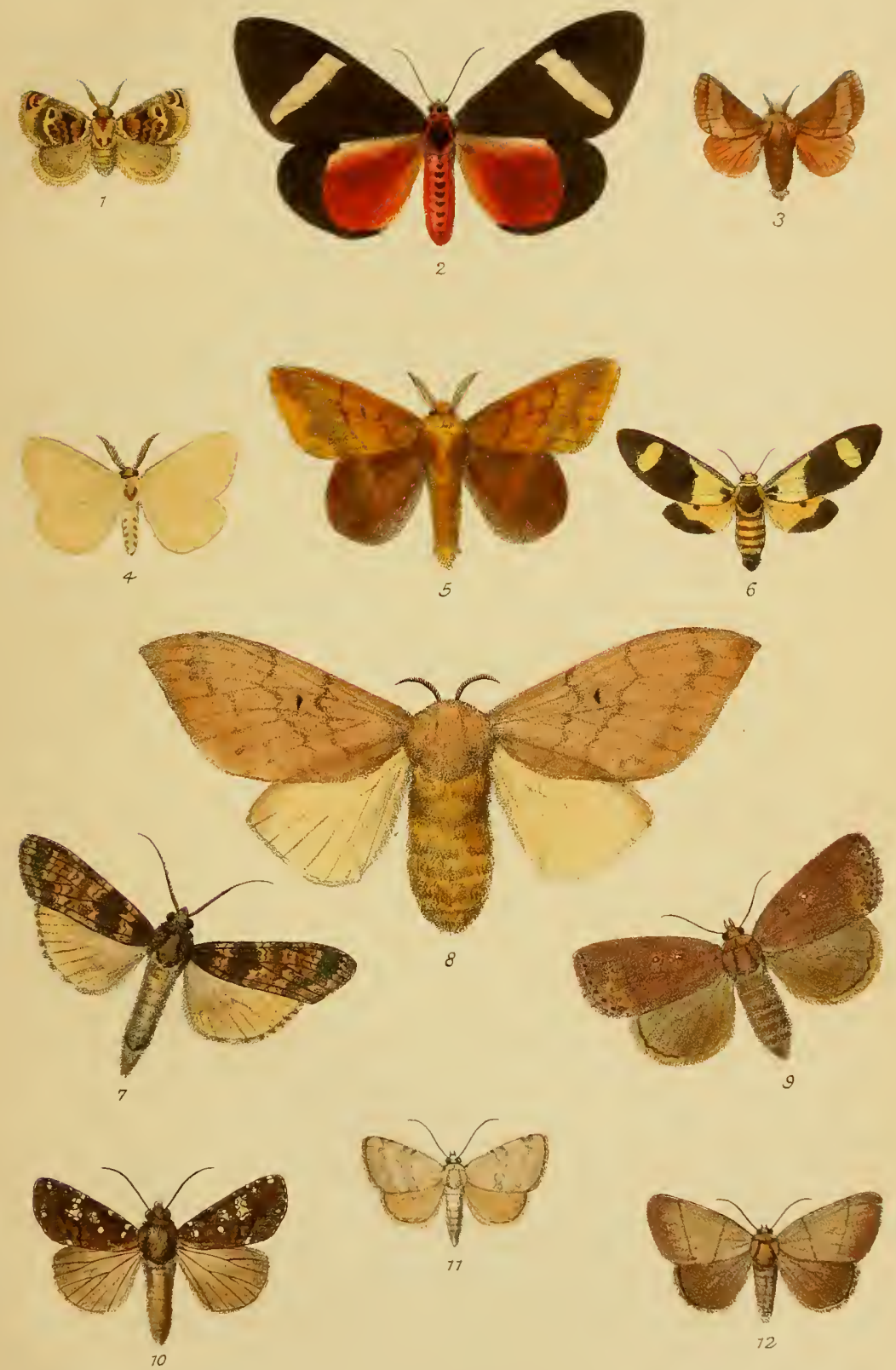

W.Purkiss lith. 




\section{PLATE III.}

Fig. $\quad$ Page

1. Ochropleura talda . . . . . . . . . . . 33

2. Taraehe perta . . . . . . . . . . . . 36

3. Meliana bertha . . . . . . . . . . . 34

4. Xanthoptera allecta . . . . . . . . . . 36

5. Calobochyla silona . . . . . . . . . . 40

6. Xanthoptera eolla . . . . . . . . . . 35

7. Cirroehrista saltusalis . . . . . . . . . . 43

8. Trisula magnifiea . . . . . . . . . . . . . 38

9. Coptobasis leonalis . . . . . . . . . . 45

10. Gonitis leona . . . . . . . . . . . . 36

11. Hydrillodes? janalis . . . . . . . . . . 41

12. Birtha talusina . . . . . . . . . . . 37

13. Hypena? duealis . . . . . . . . . . . 40

14. Hypena saltalis . . . . . . . . . . . 40

15. Focilla docta . . . . . . . . . . . 39 

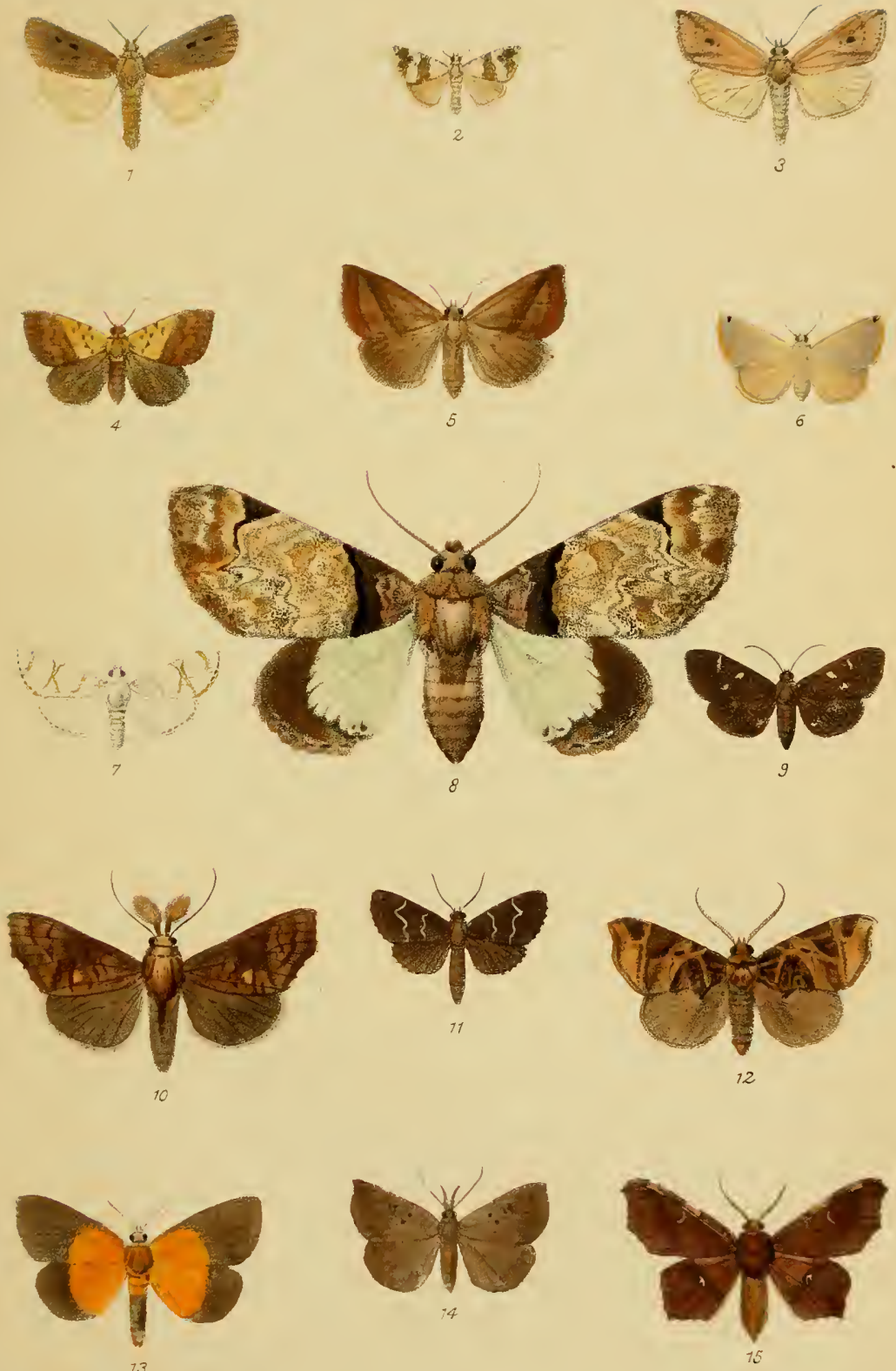





QI Schaus, William, 1859557 On a collection of SiS53S3 erra Leone Lepidoptera. Ent. 
SMITHSONIAN INSTITUTION LIBRARIES 